\title{
Ethical customer relationships: A comparative analysis of US and French organisations using permission-based e-mail marketing
}

Received: 27th June, 2002

\section{Teresa Waring}

is a lecturer in information systems at the University of Newcastle upon Tyne Business School. She holds BSc and MSc degrees from Durham and Sunderland Universities respectively and has a PhD from Northumbria University. With over 15 years' extensive teaching and research experience in the area of information systems management she is currently Director of Quality and Learning resources in the Business School. Her research and consultancy experience includes both the private and public sectors and her main focus of interest is the implementation of integrated information systems.

\section{Antoine Martinez}

has completed a postgraduate course of studies in France, where he obtained a Master's Degree from the Grenoble Graduate Business School in 2002. He also holds an MA with distinction in international business management from the University of Newcastle upon Tyne, UK. In recent years Antoine has performed consultancy with a number of business-to-business (b2b) firms such as Totalfinaelf, A.Raymond Group, Renault Trucks and AB Volvo. His main research interests lie in marketing management (and all the ways this discipline can be explored and implemented), and market surveys in a b2b environment.

\begin{abstract}
This paper examines a specific development in direct marketing on the Internet that aims at building more ethical customer relationships - permission-based e-mail marketing. The aims of the paper are first to explore the concept of ethical behaviour and how it relates to the Internet. Secondly it examines the literature on how permission-based e-mail marketing arose and what is considered to be good practice. Thirdly it presents primary research conducted over a six-month period that investigated how permission-based e-mail marketing is carried out by a sample of organisations in both the USA and France and examined two e-mail marketing service bureaux that offered a complete, outsourced solution for companies in Europe. Finally, it discusses the success of permission-based e-mail marketing for the organisations investigated and how other companies could learn from their experience of adopting a more ethical practice.
\end{abstract}

\section{INTRODUCTION}

Dr Teresa Waring University of Newcastle upon Tyne Business School, Armstrong Building, University of Newcastle, NE1 7RU, UK.

Tel: $+44(0) 1912226187$; Fax: +44 (0)191 2228131; e-mail:t.s.waring@ncl.ac.uk
Direct marketing via the Internet has been growing at a phenomenal rate over the last five years as more customers both in the USA and Europe begin to go online. Historically, organisations have communicated with their customers through various media that follow a passive one-to-many communication model. This model has allowed those organisations to reach many current and potential customers, segmented or not, through marketing efforts that permit only limited forms of feedback from customers.

One of the defining qualities of 
marketer-customer interaction over the Internet is the ability to develop relationships with customers. Marketers can use this unique medium to collect market data, to question, listen to and respond to customers in ways that had never been previously possible. There have, however, been examples of bad practice that have angered many of the Internet community and made potential customers highly suspicious of any attempts to foster customer relationships. A number of organisations are now becoming increasingly aware that they need to proceed more cautiously and take a more ethical approach towards marketing their products and services.

This paper examines one specific development in building more ethical customer relationships permission-based e-mail marketing. The aims of the paper are first to explore the concept of ethical behaviour and how it relates to the Internet. Secondly it examines the literature on how permission-based e-mail marketing arose and what is considered to be good practice. Thirdly it presents primary research conducted over a six-month period that investigated how permission-based e-mail marketing is carried out by a sample of organisations in both the USA and France and examined two e-mail marketing service bureaux that offered a complete outsourced solution for companies in Europe. Finally, it discusses the success of permission-based e-mail marketing for the organisations investigated and how other companies could learn from their experience of adopting a more ethical practice.

\section{ETHICAL ISSUES AND THE INTERNET}

Ethics is a branch of philosophy that deals with what is considered to be right and wrong. Ethics is highly contextual and with the passage of time society is continually updating its ethical guidelines. What is unethical is not necessarily illegal, however, and in many instances individuals are faced with ethical decisions that do not fall into the bracket of law breaking. Communications technology and the Internet are facilitating easy access to people in their homes and at work across the world and through this new perspectives on what is right and wrong in the global society are being developed.

'The Internet was once a community of tightly knit academics and scientists with a shared social consensus and, therefore, informal rules of conduct. Now that it has burgeoned into a world of 20 million people, the same destructive and deviant behaviour found in the real world is found in the virtual one.'

This quote from Murray highlights the fact that much of what takes place on the Internet is highly unstructured and more recent e-business is so new that the legal, ethical and other public policy issues that are necessary for its existence are still evolving. The spread of e-business has created many new ethical situations, eg putting 'cookies on customers PCs' or monitoring staff e-mail and whether these actions are considered unethical depends upon the organisation, country, culture, value systems etc. $^{2}$

In the globalised economy companies operate under increasing environmental pressures. These pressures are not new but with the introduction of the Internet as a new and some would say better distribution channel that can compete against traditional ones the need to attract and keep customers online is essential. In their race for customer acquisition many companies have developed practices that raise ethical 
issues and these ethical issues are not necessarily the same through the world. ${ }^{3}$ An attempt to organise IT ethical issues into a framework can be seen in the work of Mason et al. ${ }^{4}$ who categorised ethical issues into privacy, accuracy, property and accessibility:

- privacy: collection, storage and dissemination of information about individuals

- accuracy: authenticity, fidelity and accuracy of information collected and processed

- property: ownership and value of information and intellectual property

- accessibility: right to access information and payment of fees to access it.

Ethics has assumed a new dimension of importance as e-business opens up a new spectrum of unregulated activities and one major area for concern has been in marketing on the Internet.

\section{MARKETING ON THE INTERNET}

The term 'marketing' encompasses the 'process of planning and executing the conception, pricing, promotion, and distribution of ideas, goods, or services in order to create exchanges that satisfy individual and organisational goals, ${ }^{5}$

This definition assumes a set of marketing tools that the firm can use to pursue its marketing objectives. More explicitly, McCarthy classified these tools into four broad groups that he called the four Ps of marketing: product, price, place and promotion. ${ }^{6}$ These four Ps constitute the basis on which most marketing theories are built.

As a new marketing medium, the Internet has the potential to change the way companies do business with their customers. In the past businesses have communicated with their customers through various media that follow a passive one-to-many communication model. The Internet has changed this relationship in a radical way. The interactivity allowed by the Internet gives businesses the opportunity to deliver real-time, personalised information to any one consumer ${ }^{7}$ and at the same time customers can use the Internet to access any information available online to learn about sellers and their products. ${ }^{8}$ Baldenweck has clearly demonstrated the impact of the Internet upon the 'four Ps' as shown in Figure $1 .^{9}$

\section{THE GROWTH OF DIRECT MARKETING}

According to Kotler and Armstrong ${ }^{11}$ direct marketing consists of:

\section{'Direct connections with carefully targeted individual consumers to both obtain an immediate response and cultivate lasting customer relationships.'}

Direct marketing is not a new phenomenon and dates back to the industrial revolution. ${ }^{12}$ In the 1960 s, however, there was the growth of 'the catalogue business' followed by the development of market segmentation and the need of companies to present products that were only targeted to specific groups of consumers.

Fletcher et al. ${ }^{13}$ pointed out that since the end of the 1980s over 90 per cent of all companies have been using some form of direct marketing and it has become an integrated part of their marketing strategy to develop customer relationships.

IT has vastly improved the effectiveness of direct marketing and, with the development of databases, companies not only have ready access to customers' names and addresses but also 


\begin{tabular}{|c|c|}
\hline $\begin{array}{l}\text { Product } \\
\text { Product variety } \\
\text { Quality } \\
\text { Features and options } \\
\text { Style and design } \\
\text { Brand name } \\
\text { Packaging } \\
\text { Sizes } \\
\text { Warranties } \\
\text { Services and returns }\end{array}$ & $\begin{array}{l}\text { Place } \\
\text { Distribution channels } \\
\text { Coverage } \\
\text { Assortments } \\
\text { Locations } \\
\text { Stocks and warehouses } \\
\text { Transport } \\
\end{array}$ \\
\hline $\begin{array}{l}\text { Price } \\
\text { List price } \\
\text { Discounts } \\
\text { Allowances } \\
\text { Payment period } \\
\text { Credit terms }\end{array}$ & $\begin{array}{l}\text { Promotion } \\
\text { Advertising } \\
\text { Sales force } \\
\text { Sales promotion } \\
\text { Public relations }\end{array}$ \\
\hline
\end{tabular}

From traditional marketing ...

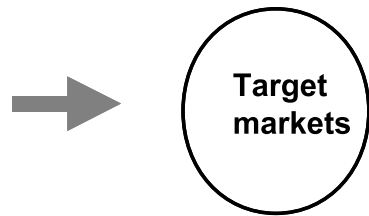

\section{...To Web marketing}

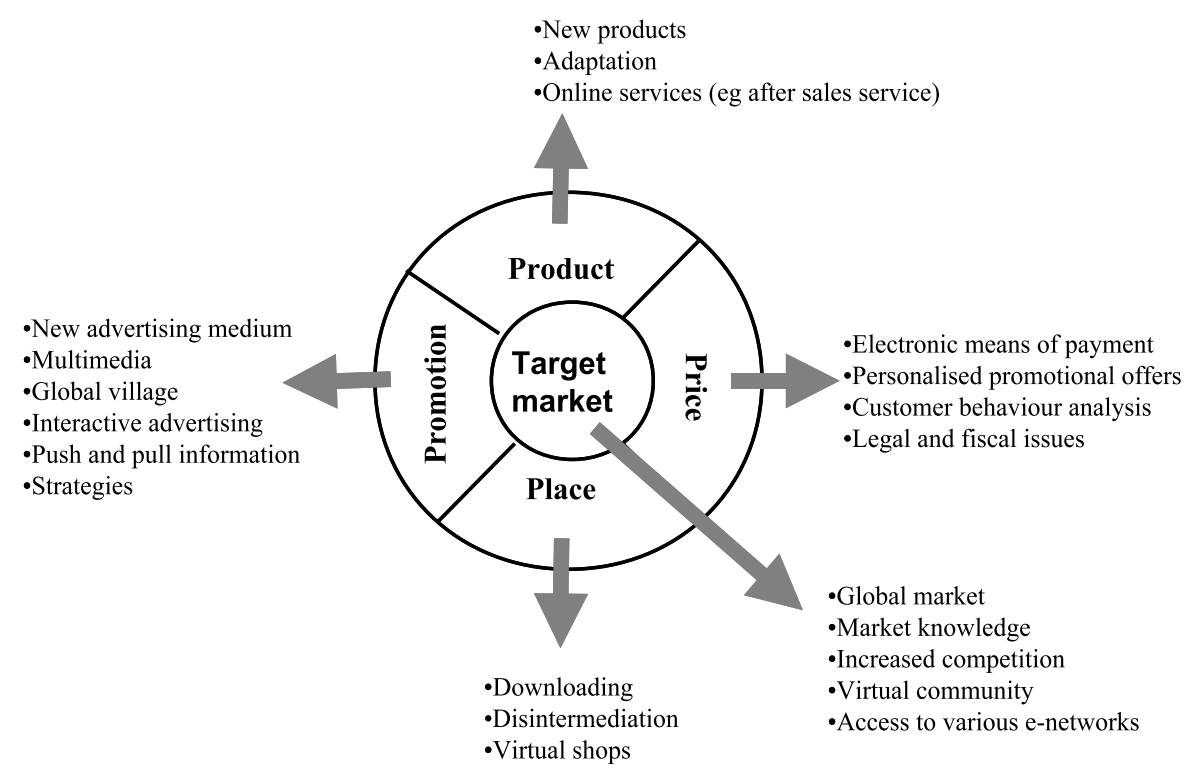

Figure 1: Changing market models ${ }^{10}$

collect much other personal and purchasing information, thus building a profile of the consumer as an individual. ${ }^{14}$ Kotler and Armstrong also point out that the increasing sophistication of databases to include not only demographic and geographic information but psychographic and behavioural data allows companies to use the information to locate new potential customers and tailor products and services to their perceived needs. ${ }^{15}$

Direct marketing has many forms as can be seen from Figure 2.

It is the growth of the Internet and its potential to reach a global market online 


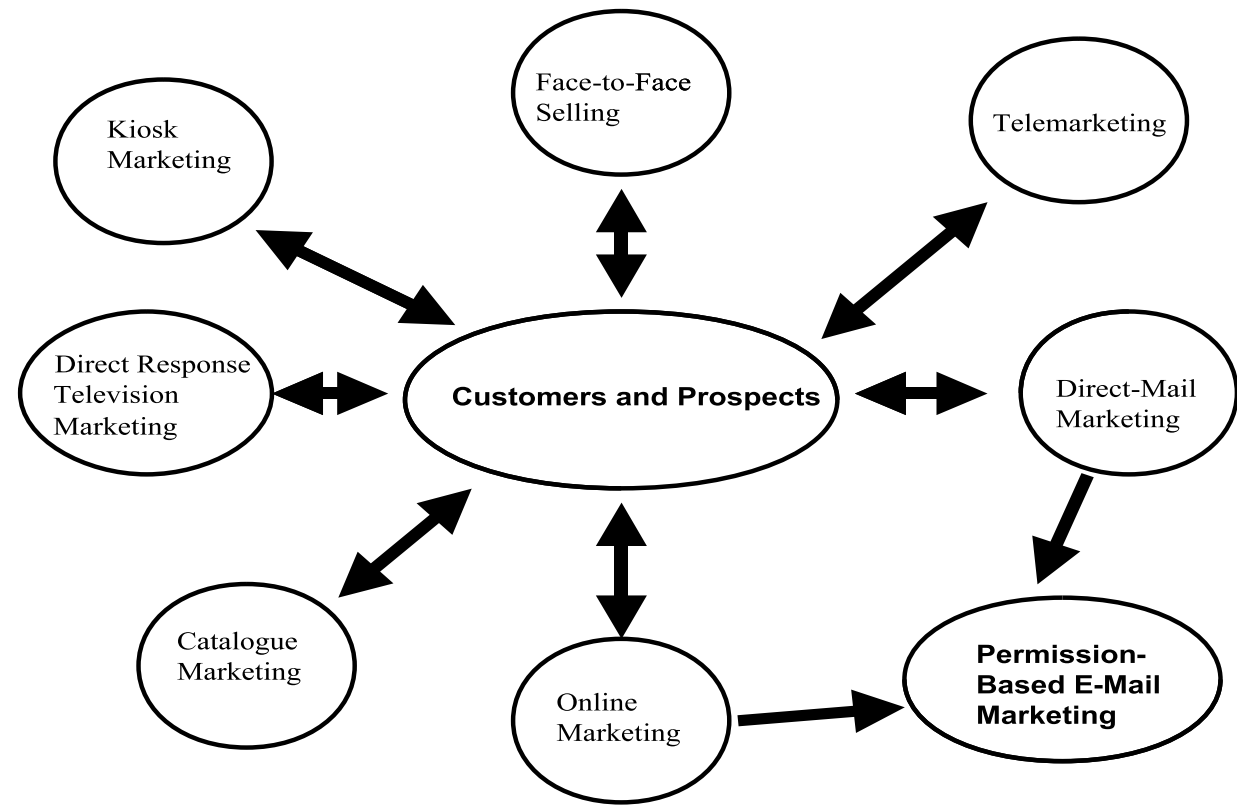

Figure 2: The major forms of direct marketing ${ }^{16}$

that has excited the marketing community and by using many of the principles of direct mail marketing the new phenomenon of permission-based e-mail marketing has arisen.

\section{PERMISSION-BASED E-MAIL MARKETING}

E-mail has been available since the Internet began and is 'not subject to some of the technical changes that might force people to update their Web browsers every three months'. ${ }^{17}$ As a result, e-mail can be considered both stable and reliable. For many people e-mail is their main reason for being on the Internet, as it is cheap and convenient and companies have come to recognise this. The commercial e-mail market is predicted to rise to an estimated US\$7.3bn in 2005, cannibalising direct mail revenues by 13 per cent. ${ }^{18}$ Slack argues:

'It cannot be denied that nowadays businesses are beginning to perceive e-mail marketing as the silver bullet for acquisition and retention strategies: it is fast, cost effective and provides immediate feedback. ${ }^{19}$

Numerous companies have been impressed by the high rate of response obtained when sending e-mails and in a 2001 report 10 per cent of e-mail recipients click through to the sender's Web page, and about 2.5 per cent of those recipients make a purchase during the visit. ${ }^{20}$ Not all e-mails, however, are equally effective.

Forrester Research stress the important role of e-mail in opening a dialogue with customers and gradually building a relationship that will eventually allow more personal information to be gained. ${ }^{21}$ Many organisations, however, are using it indiscriminately to market products aggressively and bombard consumers with unsolicited e-mails. The potential to develop better customer relationships is being eroded by unreflective practice.

Consumers are discerning and have experienced aggressive direct marketing 
through unsolicited 'snail mail' and telemarketing and they are not prepared to accept 'spamming' on the Internet. ${ }^{22}$ Organisations need to adopt better practice if they are to acquire and retain customers and one way could be through permission-based e-mail marketing.

Meta Group ${ }^{23}$ define a permission e-mail as:

'A promotional e-mail whose recipients consent to receive commercial messages from the sender, typically by signing up at the company's website.'

This new form of direct marketing is well established in the USA and is beginning to develop in Europe. It enables companies to achieve higher response rates because consumers give their own details freely. ${ }^{24}$ In this respect, e-mail marketing uses what is called 'push technology' in order to deliver targeted messages and it is the consumer who defines what interests them (often by filling out online questionnaires) and as a result are only sent relevant information or messages. ${ }^{25}$

Compared to other online marketing vehicles, such as Web banner advertisements, permission e-mail marketing delivers superior performance and more measurable business impact and when approached responsibly and in an ethical manner can achieve:

- 15 per cent clickthrough rates on e-mail campaigns (compared to 1 per cent or below with Web banner advertisements)

- conversion rates (for surveys, newsletter sign-ups, e-commerce sales etc) of 5 per cent or better. ${ }^{26}$

Unlike Web banners, permission-based e-mail puts the marketer back in control of what messages the consumer receives and when they receive them. ${ }^{27}$ In addition, cost per message sent for permission e-mail allows marketers to improve their marketing economies by five times or more compared to direct mail and by as much as 20 times compared to Web banners. ${ }^{28}$

As more marketing is done on the Internet and e-mail marketing is studied further it is possible to understand more about the buying behaviour of the consumers who respond to e-mail offers. For example, Cross and Nassef ${ }^{29}$ have identified two specific categories:

— the 'hot clickers' who are quick respondents and usually act on an e-mail promotion within 24 hours. If they like the offer, they will even act as advocates, forwarding the message to friends and relatives who may also be interested in the offer. Such behaviour is, however, difficult to predict and there is no consistent buying pattern

- the 'warm clickers' who will think about a specific offer they received, often taking up to three days to respond. They also like to receive more information about products and services before making commitments. These buyers make up for their slower response time, however, by being predictable long-term performers and it is possible to predict their annual buying patterns within 5 per cent.

Generally speaking, and whatever e-mail consumer category is taken into account, $\operatorname{Kannan}^{30}$ predicts that a very large percentage of the sales realised through direct marketing in the forthcoming years will come specifically from permission-based e-mail marketing. Brondmo $^{31}$ suggests this is because consumers since the 1970s have lost the personal relationship with their local stores as the growth of retail malls, 
supermarkets etc has impacted upon communities. Buying has become much less of a social experience. Consumers, Brondmo ${ }^{32}$ argues, want one-to-one communication with the vendors and see e-mail as one way of re-establishing this relationship. Organisations who recognise this need and enter into voluntary communication with prospective buyers that is innovative, fun, participatory and gives tangible benefits to the consumer for their time and attention will not only acquire new customers but will also retain them. ${ }^{33}$

\section{BEST PRACTICE IN PERMISSION-BASED E-MAIL MARKETING}

In order to develop a good customer relationship and maximise the chances of retaining customers there is a need to consider how best to use

permission-based e-mail. Obviously, companies must balance their requirements to sell goods or services against customers' personal needs. They need to act ethically too. With this in mind the following practice has been identified from the literature.

Create a mailing list: E-mail marketing requires a mailing list that provides details and characteristics of potential customers. The difficulty is how that list is acquired. Sant ${ }^{34}$ suggests that it is much better to use e-mail addresses of people who have 'opted in' to schemes rather than those of names acquired surreptitiously. Thus an ethical company starting out looking for e-mail lists and buying from another company should always ask the question 'how were the members of the list recruited?'.

Rosenthal ${ }^{35}$ adds that every opportunity to get opt-in permission from recipients should be made and incentives provided to do so.

Segment the lists: Weedman ${ }^{36}$ suggests that once an e-mail list has been acquired it should then be segmented in order to focus better upon the people on it and make e-mails relevant to the consumer. Sant ${ }^{37}$ suggests this can be done in a number of ways geodemographics, personal profile, interests/attitudes, Web-surfing behaviour and activity, clickthrough data, purchases etc.

Focus on the customer: Skarzenski ${ }^{38}$ argues that too many people focusing on the customer would appear obvious. In reality, however, marketers tend to concentrate on the company directors' desires to maximise profits above all else and promote the company. This attitude often leads to e-mail messages with an inner-directed orientation that often start with: "We are proud to announce...' or 'Our new product...' or ' $\mathrm{XYZ}$ corporation is the leader in.... As a result, these e-mails fail to engage the reader in the first few vital seconds that they begin reading the message.

Create targeted offers: Potential customers will be more likely to respond to messages that match their interests. Thus it is essential for the company to create specific messages for specific audiences. ${ }^{39}$ The process is basically a matter of relationship marketing and if managed sensitively can strengthen a company-customer relationship by not bombarding the consumer with irrelevant material.

Personalise the message: 'In the world of direct e-mail marketing, everyone is unique and one size does not fit all. ${ }^{40}$ This basic principle seems straightforward. Rosenthal, ${ }^{41}$ however, suggests that for many companies using e-mail marketing and delivering to millions of recipients in a few hours it is easy to lose sight of the fact that each recipient is an individual with different interests and characteristics. Thus, by 
failing to personalise a message a company can transform a growing audience of responsive, potential customers into an angry mass who automatically delete companies' messages without reading them.

Favour quality (over quantity): If a company wants to increase response rates, it has to create genuine offers for unique products, useful information, compelling content, special pricing or gifts. Reading e-mails takes time and effort and if the customer is not clearly identified and the delivered offer is not seen as valuable then the customer is likely to 'opt out' of the mailing list. ${ }^{42}$

Call to action: An e-mail marketing campaign's primary objective should be to get potential customers to take action. MacPherson ${ }^{43}$ suggests that the outgoing message should include more than one call to action eg 'click here to download your free trial software', 'link to more information', 'buy', 'join', 'communicate with a sales representative' etc.

Text versus HTML - give the choice: The difference between text and HTML lies in the fact that HTML-capable e-mails provide remarkable advantages over 'plain' e-mails, such as being in full colour with embedded links and forms within the messages themselves. ${ }^{44}$ Nowadays, almost 60 per cent of e-mail users have the ability to receive HTML e-mails and they appear to get twice the response rate of text e-mails. ${ }^{45}$

Nevertheless, HTML e-mail excludes an estimated 30-40 per cent of the e-mail population and therefore it is essential for companies using this form of marketing to provide a text alternative. Besides, some people prefer text to graphics. ${ }^{46}$

Avoid spam: 'Spam' is the slang term for bulk unsolicited commercial e-mail (BUCE).$^{47}$ More relevantly to this subject, spam is defined as: 'Promotional bulk e-mail whose recipients never consented to a marketing relationship with the sending company'. ${ }^{48}$ Although not illegal, spam can be viewed as being unethical by many of the recipients and can damage a company's reputation. ${ }^{49}$ Rosenthal ${ }^{50}$ suggests that spam can infect the mind of the recipient into a predisposition against all e-mail marketing and the analogy can be drawn with unsolicited mail delivered through a customer's letterbox at home - much of which ends in the bin without being read. Amazon.com learned to their cost in the early days how damaging spam can be and now have a more ethical approach to e-mailing customers. ${ }^{51}$ There are also ISP-blocking technologies that can stop unsolicited e-mails even before they reach the recipient. ${ }^{52}$

Respect the customer: It is important that companies respect the needs of customers and their right of privacy. Companies do need to know their customers to ensure deliveries, payments and to avoid fraud. A customer, however, has the right to sever all ties with the online company once the purchase has been made or even to visit a website and browse without leaving their details. There are two alternatives to these issues:

— the 'opt-in' list where customers are only contacted when they agree to become part of an e-mail list and get explicit information that they have asked for ${ }^{53}$

- the 'opt-out' list where every e-mail sent to customers includes the possibility for them to unsubscribe, access and change data. Bly et al. ${ }^{54}$ give a model opt-out statement that can be used when carrying out an e-mail marketing campaign: 'We respect your online time and privacy and pledge not to abuse this medium. If you prefer not to receive further e-mails of this type from us, please reply to this e-mail and type "Remove" in the subject line'. 
Monitor and report: Tracking the permission-based e-mail marketing campaign and the action of customers is essential. Bly et al. ${ }^{55}$ suggest three main measurements:

- the 'click through' that tells the marketer how many people (out of those who received the message) clicked on a link in the e-mail to a specific site, page or form on the Web

- the 'replies' tells the marketer how many people (out of those who clicked through to a response form) completed the form and submitted it to the marketer

- the third measurement is sales or enquiries. This tells the marketer how many people (out of those who completed the form) actually ordered a product or requested more information, such as product literature or price quote

One very controversial, though ingenious, means of tracking customers' online habits and behaviour while delivering customised information and services is the use of 'cookies'. Cookies are files of information that reside on the customer's PC and collect information on behalf of the marketing company.

Marketers can use this information to determine the user's preferences and can provide advertisements and make special offers based on those preferences. ${ }^{56}$ Cookies have come under scrutiny by governments in recent years and a number have introduced legislation to control their growth and protect the privacy of individuals. ${ }^{57}$

Permission-based e-mail marketing is a relatively recent phenomenon and much of the literature on the subject and considered best practice has emerged from the USA. Practice in the USA does not necessarily translate directly into Europe and it is the purpose of the next section to compare a sample of US companies using permission-based e-mail marketing with a sample from France and examine whether there is any notable difference in their approach and how this contributes to understanding ethical best practice in a European context.

\section{METHODOLOGY}

E-business is growing at a phenomenal rate and any research done in the subject area is likely to be outdated in a relatively short period of time. The research discussed in this paper was carried out over a six-month period between March and September, 2001. Two approaches to data collection were adopted - in-depth interviews and online e-mail data collection.

In-depth interviews: six companies in France were contacted to request interviews about their approach to permission-based e-mail marketing. Two companies out of six approached who used permission-based e-mail agreed to be interviewed with respect to their practice. The companies were relatively new marketing service bureaux offering a complete outsourced solution for companies who needed assistance with their customer relationship management through permission e-mail marketing campaigns. The in-depth interviews with the chief executive of E-mail Vision (Paris) and the PR manager of Cabestan (Paris) lasted for one and a half hours and gave insight into how these companies approached and implemented permission-based e-mail marketing. The companies who refused to be interviewed gave reasons of confidentiality. Analysis of these interviews used the criteria of good practice, ethical practice along with efficiency and effectiveness of the marketing approach. 
Table 1: French and US companies investigated in the study

\begin{tabular}{|c|c|}
\hline French companies & US companies \\
\hline Business-to-consumer sector & Business-to-consumer sector \\
\hline La Fnac (CDs, books, DVDs/videos, hi-fi etc) & Amazon.com (CDs, books, DVDs/videos etc) \\
\hline Chapitre.com (books) & CD Now (CDs, DVDs etc) \\
\hline Digitall.fr (CDs, DVDs, video games etc) & Dell (computers) \\
\hline Yves Rocher (cosmetics, fragrances) & $\begin{array}{l}\text { Columbia Records-Sony Music (information } \\
\text { concerning musical events) }\end{array}$ \\
\hline Lancome France (cosmetics, fragrances) & Victoria's Secret (women's clothing, underwear, \\
\hline $\begin{array}{l}\text { Le Club des createurs de beaute } \\
\text { (CCB-Paris)(cosmetics, fragrances) }\end{array}$ & fragrances etc.) \\
\hline $\begin{array}{l}\text { Decathlon (sports articles) } \\
\text { Le Club Med (travel and travel goods) }\end{array}$ & $\begin{array}{l}\text { Petco.com (products and food for all sorts of } \\
\text { pets) }\end{array}$ \\
\hline Business-to-business sector & Business-to-business sector \\
\hline \multirow{3}{*}{$\begin{array}{l}\text { UpDesk.net (website dedicated to the new } \\
\text { economy and supplying information about this } \\
\text { subject) }\end{array}$} & $\begin{array}{l}\text { IBM (provides news and updates related to the } \\
\text { activities in which IBM has an interest) }\end{array}$ \\
\hline & $\begin{array}{l}\text { Ziff-Davis: the Best of ZDNet (product reviews, } \\
\text { downloads, shopping deals, special reports on } \\
\text { new technologies) }\end{array}$ \\
\hline & $\begin{array}{l}\text { Ziff-Davis: Anchordesk (computing news and } \\
\text { trends with concise summaries and expert } \\
\text { analysis) }\end{array}$ \\
\hline Non-governmental organisations & Non-governmental organisations \\
\hline $\begin{array}{l}\text { Medecins Sans Frontieres (NGO acting against } \\
\text { war, poverty and injustice around the world) }\end{array}$ & $\begin{array}{l}\text { Greenpeace (NGO promoting the protection of the } \\
\text { environment through active campaigns against } \\
\text { organisations and governments) }\end{array}$ \\
\hline
\end{tabular}

Online e-mail data collection was carried out between June and August, 2001. This involved one of the authors setting up a specific e-mail address and then registering online for a company newsletter and other information related to their specific consumer interests with 20 companies, ten from the USA and ten from France. Although a particular sector was not chosen the focus was mainly on business-to-consumer websites as shown in Table 1.

Over the three-month period e-mails were collected from the companies and then analysed using the best practice criteria synthesised from the literature. (It is recognised that the samples used are quite small but the research was exploratory and if there had been more time a much larger sample could have been used. The authors believe, however, that the results give some insight into practice within a European context.)

\section{RESULTS}

\section{The in-depth interviews}

From the point of view of the PR manager at Cabestan, permission-based e-mails must be highly personalised, not only addressing the customer by his/her name but with content that reflects their particular needs. $\mathrm{He}$ viewed permission e-mails as a major customer relationship tool that complete the company website. In fact, one of the main reasons customers visit a site is because of effective, permission e-mail marketing. The CEO of E-mail Vision supported this and added 


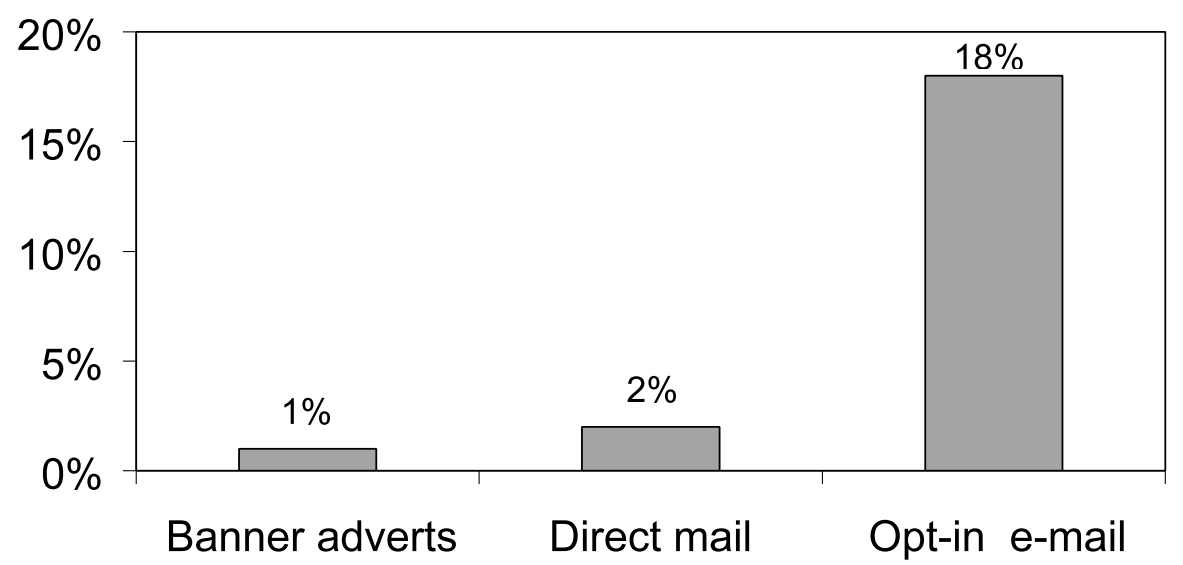

Figure 3: Average response rates for marketing methods (E-mail Vision)

'E-mail marketing maximises each customer's value over time by building long-term relationships and loyalty'. To an online company customer loyalty is extremely important.

The companies using permission-based e-mail marketing while working with an ASP (Application Service Provider) are generally charged on a cost-per-message delivered basis and this can be very low. The CEO of E-mail Vision estimated that these costs are 80 per cent lower than those connected with postal direct marketing. The standard cost of an e-mail managed by E-Mail Vision is about $€ 0.03$. Also, companies using e-mail will probably only need the service of a Web graphic designer rather than a specialised advertising agency to set up their campaigns.

The CEO of E-mail Vision believed that permission e-mail marketing is highly effective and produces a good return on investment (ROI) and figures given by the interviewees are similar to those within the literature (see Figure 3).

The CEO of Cabestan pointed to companies that they deal with, such as Bayard Press Publishers, France Loisirs and La Redoute, who have all benefited from a permission-based e-mail campaign that has not only shown a good ROI but has developed a good base for better customer relationships.

Neither interviewee expressed any doubts about the need to 'spy' on their customers while they are online. They saw this as a vital aspect of Internet marketing and believed there was the need for expertise in this area. They both argued that e-mail service providers can help in this by providing powerful hardware and software to track customers and by outsourcing marketing campaigns to these specialist organisations businesses can take advantage of skills and infrastructure that they do not possess in-house.

Cabestan explained their approach to permission e-mail marketing through the 'e-mail customer contact cycle' as shown in Figure 4.

The customer acquisition phase constitutes the starting point where the company hunts and gathers new online customers by identifying its market, creating the best offers for the business and promoting to its potential target audience. The company may already have a mailing list but may need help in building this further. It may turn to an ASP such as a brokerage service for opt-in lists. The testing phase works on the principle that by testing past offers 
2

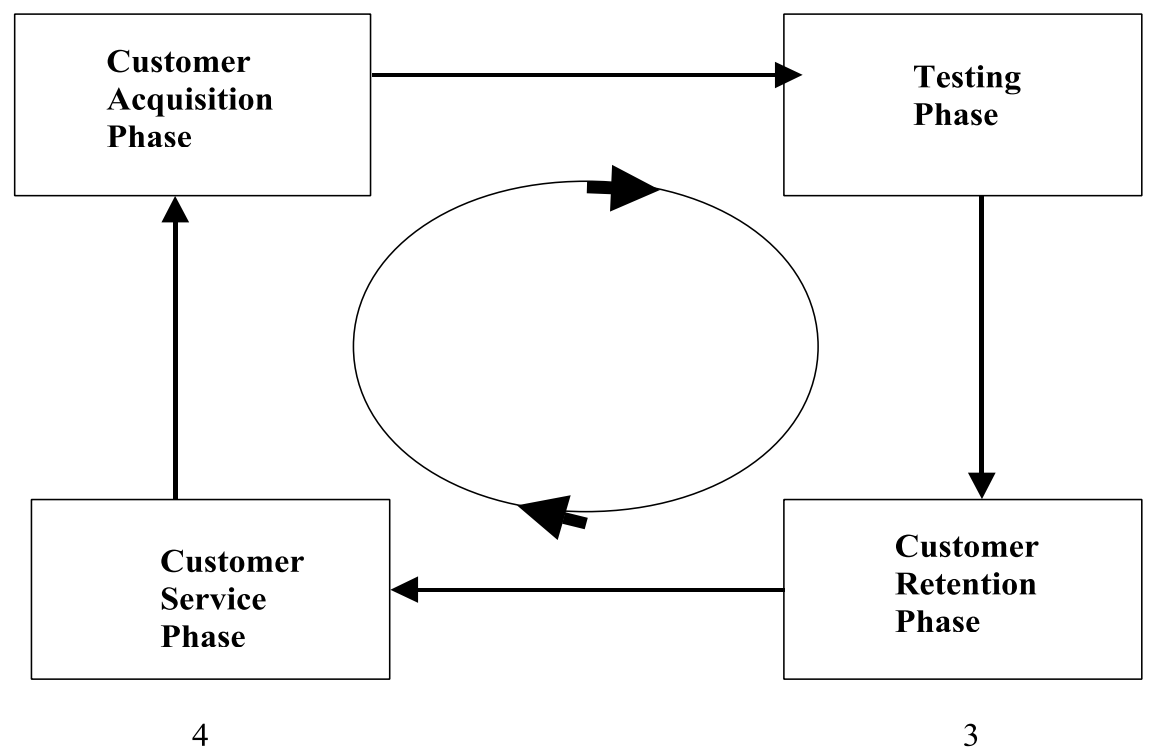

Figure 4: The e-mail customer contact cycle

and their outcomes the company will acquire a better understanding of what customers expect and therefore improve its e-mail marketing campaigns. The company then enters the profit-making stage - customer retention. This is where the company 'needs to build genuine relationships with its customers by marketing to them individually, personalising the messages and offering products that fit exclusively their wants and needs' (PR manager, Cabestan). The customer service phase completes this cycle and consists of keeping customers happy with timely responses to their messages and actions.

From a company's perspective both interviewees believed that permission e-mail has improved the performance of the direct marketing function:

'The amount of time related to the technical implementation of an e-mail campaign is ridiculously small. As soon as the customer database is available, only a few hours are required for the compulsory testing phase and, by the next day, 50,000 e-mails per hour can be sent.' (PR manager, Cabestan)
This compares with several weeks or months in traditional direct marketing methods such as catalogue marketing. The CEO of E-mail Vision suggested that an entire e-mail campaign can be designed and executed within a single week as the technology provided by an ASP enables companies to start collecting opt-in names within 48 hours and test results can be tracked in real time and conclusions delivered within 72 hours. Companies can even monitor customer reactions to e-mail campaigns by integrating customer satisfaction surveys into the message that interrogates readers' perceptions of ergonomics and content and what else they might want.

The ability to measure the effectiveness of an e-mail campaign is an aspect of this approach that is potentially seductive to companies. Traditional approaches to direct marketing have required analysis of results over weeks or months after the campaign is finished but e-mail campaigns can be analysed instantly using software tools at any point in the campaign through their Web browser. 
Neither interviewee believed that permission-based e-mail marketing will replace traditional approaches and view it as a complement to any company's marketing strategy. It is their belief that paper-based advertising media have a much better visual impact at the present and not everyone has access to computers.

\section{Online e-mail data collection}

There was a vast amount of data collected online through the e-mails received and a summary is presented in Table 2. The e-mails were analysed using criteria that the authors understood to be significant in relation to an ethical approach as well as best practice. The entries in the table refer to:

- all organisations request information at the registration point but some request much more than others: basic $=$ name, address, phone number, e-mail address; fairly detailed $=$ as before and age, gender, job, company name, size, address of company; detailed $=$ as before and details about interests, purchase details etc.

— basic personalisation: 'Dear [name of customer]'

- content of e-mails: where personal details are supplied are they used to target the customer?

\section{DISCUSSION}

All organisations that intend to do business on the Internet must recognise that developing customer relationships that respond to the needs of the consumer are essential. Rarely do online vendors meet their customers and therefore developing trust and confidence have to be of the uppermost importance if there is to be retention of their business. This is something that cannot be done overnight and requires respect for the individuals engaging in transactions. Many companies online do not have the expertise or hardware and software to develop good customer relationships.

In the USA there are at least 20 new companies that are providing specialist e-mail marketing services for businesses online. In France, Cabestan and E-mail Vision have emerged as new companies (ASPs) that are providing a service for other companies who need to progress their marketing strategy into e-mail marketing. They have recognised and applied much of the good practice identified in the literature and through the use of sophisticated software have been able to assist their clients in targeting specific sectors of markets and competing better with rivals. The ethical framework within which they work, however, is not explicit and they are focused on maximising profits for their clients.

It is fair to say that both Cabestan and E-Mail Vision rely heavily on the technology to support the customer relationship marketing strategy and companies who use their services do not need to concern themselves with logistics of their marketing campaigns. Both companies appear to use e-mail lists acquired in an ethical manner though for reasons of confidentiality the authors were unable to verify this. They see one of their roles, however, as monitors of individuals on those lists when they go online. This raises an ethical issue alluded to earlier - the issue of spying on customers and the placing of 'cookies' on their computers. From a company perspective the more detail they have on customers the better they can target products and promotions and understand what it is that motivates the customer to buy. Turban et al. ${ }^{58}$ regard cookies as being of greater concern than 


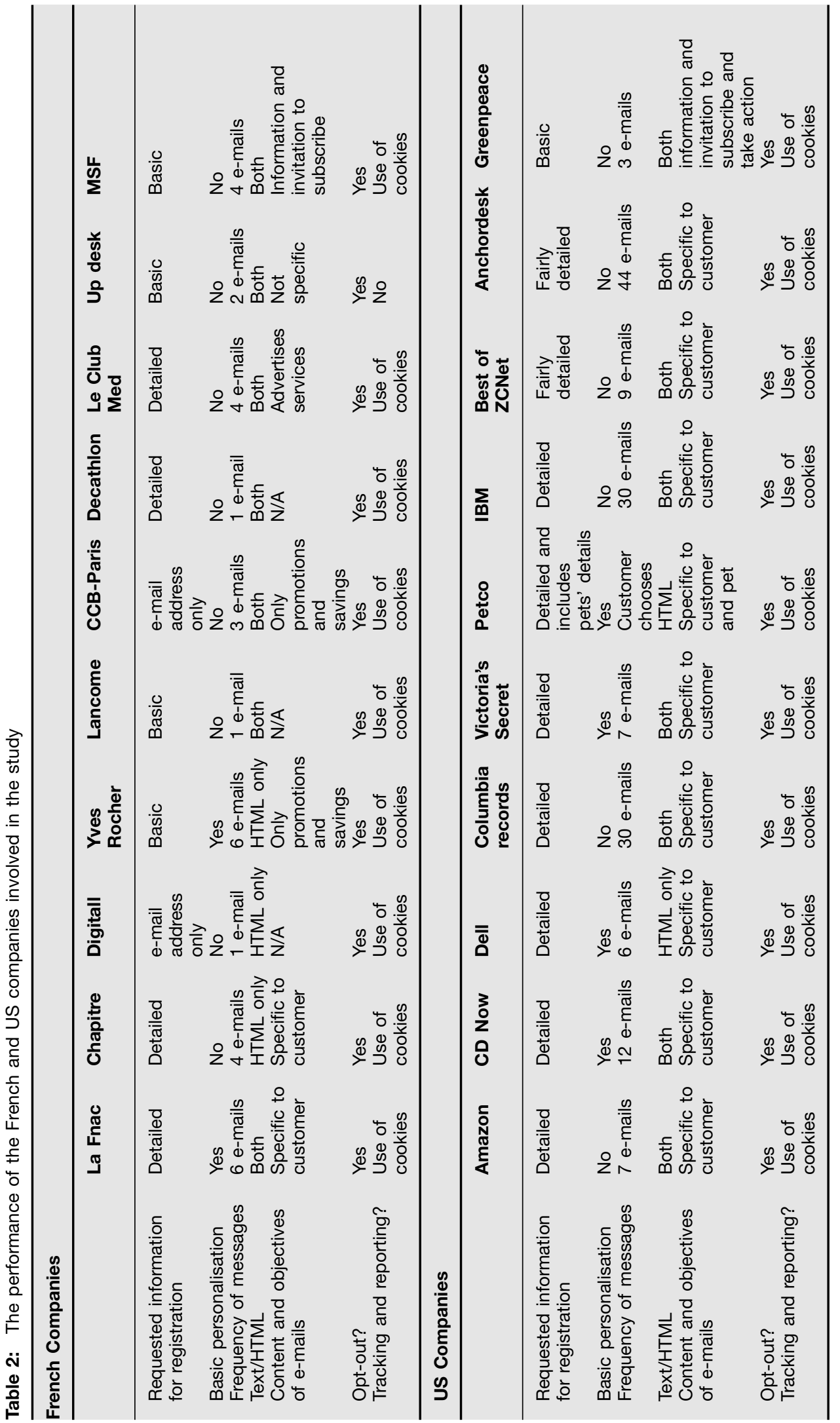


self-registration because cookies allow websites to collect private information that includes surfing patterns of users. Furthermore, personal profiles created by cookies are more accurate than self-registration on websites because it is known that over 40 per cent of all users falsify information when registering online. ${ }^{59}$ The potential for abuse of cookies has been recognised by a number of governments and in Europe on 1st March, 2002 the updated Data Protection Act 1998 came into effect. This will enable individuals to take legal action against those who process data about them without their active consent. The latest data protection legislation makes cookie technology illegal unless users are clearly told how the information is being used. This is a highly controversial move that companies feel will destroy their competitive advantage across the world as competitors in non-EU countries will continue to use them indiscriminately. It may mean inevitably that companies will move their business out of the EU in order to bypass the law and individuals' rights to privacy.

Looking now at the companies in the USA and France with which the authors registered it can be seen that the US companies appear to have adopted an approach that is customer focused and, on the surface, has an ethical dimension to it. They all collect registration information in various quantities and go on to target the content of their e-mails at the customer. This would suggest that they are actually using the registration information in a responsible manner. The authors did not receive similar e-mails from other companies within the time frame so this might indicate that the authors' details were not passed on. It is surprising, however, to note that five of the ten did not personalise those e-mails and three, IBM, Columbia and
Anchordesk, bombarded the authors with information. They all have opt-out if the customer wants to stop the e-mails. All of the US companies use cookies and this reflects the lack of legislation there. It is not seen as unethical to use cookies and is in fact regarded as an essential part of Internet business.

Of the French companies investigated it appears that practice is varied and six of the companies only collect what would be considered to be a minimum amount of information from consumers. This lack of detailed information results in e-mails that lack personalised information and content. They all contained opt-out to end the e-mails. It was also noted that the French firms on the whole contacted the authors less frequently than the US companies and therefore were less likely to establish any type of customer relationship. In 2001, however, they were all using cookies to track customers. Obviously, since March, 2002 European companies have had to re-think the 'cookie' issue and many are now informing the consumer of what they intend to do and that the alternative is re-registration each time they visit the website. Many consumers would prefer that to having their privacy invaded.

It appears that the French companies studied here have adopted much of the practice from the US but are still developing their approach. Companies such as Yves Rocher and Lancome who have a strong presence in traditional markets may feel that the Internet is complementary to their other distribution channels and hence do not need to develop online customer relationships to the degree that Amazon and Cdnow do. There is also the culture difference between France and the USA. In the USA chasing business and customers aggressively is not seen as out of the ordinary. In France, however, aggressive marketing as typified by US companies is 
practised less. This could explain the difference in frequency of messages the authors received from companies in the two countries.

\section{CONCLUSION}

Permission-based e-mail marketing is a phenomenon that still has to develop in France and it is uncertain whether it will grow as rapidly as it has in the USA. Although adopting some US ideas such as Disneyland and McDonald's, the French have not embraced them wholeheartedly and many would argue that the concepts are at odds with the French culture and psyche. If Internet marketing is not developed in a specifically French manner then companies will feel uneasy with the process and potential customers will be lost. It is important for all companies to learn from US experience but to think very carefully about customers in their own specific markets. Culture and tradition play a major role in the adoption of new methods of communication and permission-based e-mail marketing will only be ethical if practice takes account of this.

\section{References}

1 Murray, B. (1995) 'Knowledge machines: Language and information in a technological society', Longman, London and New York, p. 161.

2 Turban, E., King, D., Lee, J., Warkentin, M. and Chung, H. M. (2002) 'Electronic commerce; A managerial perspective', Prentice Hall, New Jersey.

3 Ibid.

4 Mason, R. O., Mason, F. M. and Culnan, M. J. (1995) 'Ethics of information management', Sage Publications, Thousand Oaks, California.

5 Bennett, P. D. (1995) 'Dictionary of marketing terms', 2nd ed., American Marketing Association, Chicago.

6 McCarthy, E. J. (1996) 'Basic marketing: A managerial approach', 12th ed., Irwin, Homewood, IL.

7 Jones, N. (1996) 'Talking pages', Marketing Week, Vol. 19, No. 18, pp. 27-28.
8 Sheth, J. N. and Parvatiyar, A. (2000) 'Handbook of relationship marketing', Sage, London.

9 Baldenweck, M. (2001) 'Internet: Electronic commerce and e-business', Annual Conference on Information Systems of the Public Health National School, 4-6th March, Rennes, France, p. 4.

10 Ibid.

11 Kotler, P. and Armstrong, G. (2001) 'Principles of marketing', 9th ed., Prentice Hall, New Jersey, p.617

12 Petrison, L. A., Blattberg, R. C. and Wang, P. (1993) 'Database marketing: Past, present and future', Journal of Direct Marketing, Vol. 7, No. 3, pp. 27-43.

13 Fletcher, K., Wheeler, C. and Wright, J. (1991) 'Database marketing: A channel, a medium or a strategic approach?', International Journal of Advertising, Vol. 10, No 2, pp. 117-127.

14 Fitzgerald, M. and Arnott, D. (2000) 'Marketing communications classics', Business Press, London.

15 Kotler and Armstrong (2001) op. cit.

16 Adapted from Kotler and Armstrong (2001) op. cit.

17 Walker, M. (2000) 'The top 200 web sites for marketing, Kogan Page (Illustra Guides), London, p. 22.

18 Jupiter Communications, http://www.jmm.com, cited 7th July, 2001.

19 Ibid.

20 Forrester Research, http://www.forrester.com/ home/0,3257,1,FFhtml, cited 17th July, 2001.

21 Ibid.

22 Gofton, K. (2000) 'Have you got permission', Marketing, 22nd June, p. 28.

23 Meta Group \& IMT Strategies (2000) http://www.metagroup.com/cgi-bin/inetcgi/ search/disply/Article.jsp?oid=16246, cited 27th April, 2001, 'Permission e-mail: The future of direct marketing'.

24 Miller, R. (2000) 'How direct marketing can drive traffic to your site', Marketing, 12th October, p. 43.

25 Gray, R. (1997) 'Modern languages', Marketing, 6th November, pp. 27-28.

26 META Group \& IMT Strategies (2000) op. cit.

27 MacPherson, K. (2001) 'Permission-based e-mail marketing that works!', Dearborn Trade, Chicago.

28 META Group \& IMT Strategies (2000) op. cit.

29 Cross, R. and Nassef, A. (1999) 'E-mail direct marketing comes of age', Direct Marketing, Vol. 62, No. 6, October, pp. 44-45.

30 Kannan, N. (1998) 'Ten reasons why direct marketing online will rule', Direct Marketing online, http://www.directmarketing-online. com/features/archives/articles/09301998.htm, 30th September, cited 27th April, 2001.

31 Brondmo, H. P. (2000) 'The engaged customer: The new rules of Internet direct marketing', Harper Collins Publishers Inc., New York. 32 Ibid.

33 Kannan (1998) op. cit. 
34 Sant, R. (2001) 'E-mail and the permission continuum', Digitrends online, http://www.digitrends.net/marketing/13640_16128.html, 11th June, cited 15th June, 2001.

35 Rosenthal, M. M. (2001) 'The personal side of opt-in e-mail', Digitrends online, http://www.digitrends.net/marketing/13640_15276.html, 11th April, cited 15th June, 2001.

36 Weedman, M. (2001) '12 tips for successful emarketing', Digitrends online, http://www.digitrends.net/marketing/13640_159_ 74.html, 31st May, cited 15th June, 2001.

37 Sant (2001) op. cit.

38 Skarzenski, D. (2000) 'Successful e-mail: The basics work', Digitrends online, http://www.digitrends.net/marketing/13640_12695.html, 11th December, cited 11th June, 2001.

39 Weedman (2001) op. cit.

40 Ibid., p. 2.

41 Rosenthal (2001) op. cit.

42 Weedman (2001) op. cit.

43 MacPherson (2001) op. cit.

44 Rosenthal. (2001) op. cit.

45 CyberAtlas (2001) 'E-mail marketing delivering the message', CyberAtlas: Markets Advertising, online, http://cyberatlas.internet.

com/markets/advertising/article/0,1323,5941_356-

791,00.html, Spring, cited 23rd July, 2001.

46 Weedman (2001) op. cit.

47 MacPherson (2001) op. cit.

48 META Group \& IMT Strategies (2000) op. cit.

49 Weedman (2001) op. cit.

50 Rosenthal (2001) op. cit.

51 Brondmo (2000) op. cit.

52 Rosenthal (2001) op. cit.

$53 \mathrm{Ibid}$.

54 Bly, R. W., Feit, M. and Roberts, S. (2000) 'Internet direct mail: The complete guide to successful e-mail marketing campaigns', NTC Business Books, Chicago, p. 47.

55 Bly et al. (2000) op. cit.

56 Sheth and Parvatiyar (2000) op. cit.

57 Kelly, L. (2002) 'Cookies crumble under data protection', http://www.vnunet.com/news/107416, accessed 7th May, 2002.

58 Turban et al. (2002) op cit.

59 Graphics, Visualisation and Usability (GVU) Centre at Georgia Tech University, 1998, http://cc.gatech.edu/gv/user_surveys. 
